\title{
Research from across the life-cycle of glass
}

\author{
M. Overend $₫$ - J. Belis $₫$ - C. Louter $(\mathbb{D}$ - \\ J. H. Nielsen 1 J. Schneider $(\mathbb{D}$
}

Published online: 12 March 2018

(C) Springer International Publishing AG, part of Springer Nature 2018

Barely 20 months after the publication of the first ever issue of Glass Structures \& Engineering, (GS\&E) we find ourselves with five issues, containing a total of over 800 pages of double-blind peer-reviewed leading-edge research and trailblazing practical applications of structural glass. This is topped with GS\&E's recent indexing in the Emerging Sources Citation Index, which provides a further mark of quality and ensures a high exposure of the papers, including to online author-level metrics, such as h-index calculators. The publishers and editors have clearly contributed to this rising trajectory, but the success is largely due to the high quality and exciting papers and the insightful and constructive reviews you have submitted; please keep them coming.

\section{Overend $(\varangle)$}

University of Cambridge, Cambridge, UK

e-mail:mo318@cam.ac.uk

J. Belis

Ghent University, Ghent, Belgium

e-mail: Jan.Belis@UGent.be

J. Belis

Eindhoven University of Technology, Eindhoven, The

Netherlands

\section{Louter}

Delft University of Technology, Delft, The Netherlands e-mail: Christian.Louter@TUDelft.nl

\section{J. H. Nielsen}

Technical University of Denmark, Lyngby, Denmark e-mail: jhn@byg.dtu.dk

\section{J. Schneider}

Technical University of Darmstadt, Darmstadt, Germany e-mail: schneider@ismd.tu-darmstadt.de
As a sharp-eyed reader you will have noticed that GS\&E is published bi-annually with one issue linked to a special theme and the other issue that encompasses the broader scope of the journal. We think this alternating approach adds valuable breadth and depth to the journal and we aim to continue this into the future. Regardless of type of issue, papers that are accepted for publication, after completing the peer-review process, are promptly uploaded on the "Online First" section of the journal and are publically accessible. This way, authors and readers can disseminate and access accepted papers without delay.

In this issue we have papers from the whole lifecycle of glass, ranging from manufacture/processing to characterisation of connections and the construction of a real-world glass building through to glass forensic engineering. The first paper by Aronen and Karvinen (2018) simulates the glass temperature before cooling and the cooling rate during tempering and illustrates how these affect the residual and transient stresses of glasses of different thicknesses. The second paper by Pourmoghaddam and Schneider (2018) assess the residual stresses in the area of the holes or cut-outs of a tempered glass plate by 3D Finite Element Analysis of the thermal tempering process. The third and fourth papers by Drass et al. (2018a,b) describe different experimental test set-ups for determining the mechanical properties of thin structural silicone joints that are used in glass connections These papers show how to identify the constitutive relationships of the silicones 
and how to determine the appropriate testing speed. The fifth paper by Cervio et al. (2018) investigates the mechanical behaviour of a novel embedded pointfixing for laminated glass under combined tensionshear load cases. The sixth paper by Oikonomopoulou et al. (2018) presents the main challenges and innovative solutions during the manufacture and construction of a real-world glass brick façade in Amsterdam. The façade comprises more than 6500 solid glass bricks bonded with thin adhesives. The seventh and final paper in this issue (Veer et al. 2018) describes the testing and forensic analysis on curved vehicle roof windows and concludes that the main cause of failure was uneven tempering of the glass, rather than spontaneous failure from NiS inclusions, which brings us full circle to the processing of glass.

\section{References}

Aronen, A., Karvinen, R.: Effect of glass temperature before cooling and cooling rate on residual stresses in tempering. Glass Struct. Eng. (2018). https://doi.org/10.1007/ s40940-017-0053-6
Cervio, M., Muciaccia, G., Rosati, G.: Tension-shear interaction domain for EVA-laminated countersunk point-fixing devices. Glass Struct. Eng. (2018). https://doi.org/10.1007/ s40940-018-0056-y

Drass, M., Schwind, G., Schneider, J., et al.: Adhesive connections in glass structures-part I: experiments and analytics on thin structural silicone. Glass Struct. Eng. (2018a). https://doi.org/10.1007/s40940-017-0046-5

Drass, M., Schwind, G., Schneider, J., et al.: Adhesive connections in glass structures-part II: material parameter identification on thin structural silicone. Glass Struct. Eng. (2018b). https://doi.org/10.1007/s40940-017-0048-3

Oikonomopoulou, F., Bristogianni, T., Veer, F.A., et al.: The construction of the Crystal Houses façade: challenges and innovations. Glass Struct. Eng. (2018). https://doi.org/10.1007/ s40940-017-0039-4

Pourmoghaddam, N.: Schneider,: Finite-element analysis of the residual stresses in tempered glass plates with holes or cut-outs. Glass Struct. Eng. (2018). https://doi.org/10.1007/ s40940-018-0055-z

Veer, F.A., Bristogianni, T., Baardolf, G.: A case study of apparently spontaneous fracture. Glass Struct. Eng. (2018). https://doi.org/10.1007/s40940-017-0047-4 